\title{
PENINGKATAN HASIL BELAJAR PKN MELALUI MODEL KOOPERATIF SNOWBALL THROWING KELAS IV SD NEGERI 163084
}

\author{
Herdawati \\ Surel: ibuherdawatispdsd@gmail.com
}

\begin{abstract}
This study aims to improve student learning outcomes on Civics subjects through the model of Cooperative Cooperative Type Snowball Throwing. The subject of this research is the fourth grade students of SD Negeri 163084 which amounted to 35, consisting of 18 siswalaki male and 17 female students. The results obtained from the learning with the method of Cooperative Type Snowball Throwing on Civics subjects in class IVmemiliki positive impact in improving student learning outcomes are marked by improvements in student learning completeness in each cycle, the cycle I as many as 20 students (79.69\%) who get value $\geq 70$, and in cycle II as many as 27 students $(87,90 \%)$ get value $\geq 70$, so in this case declared succeed.
\end{abstract}

Keywords: learning outcomes, Civics, Co-operative Snowball Throwing model.

\begin{abstract}
ABSTRAK
Penelitian ini bertujuan untuk meningkatkan hasil belajar siswa pada mata pelajaran PKn melaui model pembelajaran Kooperatif Tipe Snowball Throwing.Yang menjadi subjek pada penelitian ini adalah siswa kelas IV SD Negeri 163084 yang berjumlah 35, terdiri dari 18 siswalaki-laki dan 17 siswa perempuan. Hasil yang diperoleh dari Pembelajaran dengan metode Kooperatif Tipe Snowball Throwing pada mata pelajaran PKn di kelas IVmemiliki dampak positif dalam meningkatkan hasil belajar siswa yang ditandai dengan peningkatan ketuntasan belajar siswa dalam setiap siklus, yaitu siklus I sebanyak 20 siswa $(79,69 \%)$ yang mendapatkan nilai $\geq 70$, dan pada siklus II sebanyak 27 siswa $(87,90 \%)$ mendapatkan nilai $\geq 70$, sehingga dalam hal ini dinyatakan berhasil.
\end{abstract}

Kata Kunci: hasil belajar, PKn, model Kooperatif Snowball Throwing.

\section{PENDAHULUAN}

Dalam proses pembelajaran peneliti melakukan observasi pada mata pelajaran PKn di kelas IV SD Negeri 163084. Hasil yang diperoleh dari observasi tersebut menunjukan bahwa tidak semua siswa memahami materi-materi pelajaran PKn. Hal ini dapat dibuktikan dengan hasil ulangan siswa masih kurang memuaskan, dimana dari 35 siswa yang mengikuti ulangan hanya sekitar 37,14\% (13 siswa) yang memperoleh nilai 70-79 dan sisanya sekitar 62,867 \% (23 siswa) memperoleh nilai 51 - 69.Sementara itu Kriteria Kelulusan Minimal (KKM) pada mata pelajaran PKn adalah 70. Dengan metode ini natinya diharapkan siswa mampu menguasai dan memahami materi pelajaran PKN, sehingga dapat membetuk kepribadian yang berpikir secara kritis, rasional dan kreatif dalam menghadapi berbagai masalah, aktif dan bertanggung jawab dalam 
berbagai kegiatan kebangsaan dan kemasyarakatan, serta membentuk dan mengembangkan diri secara positif dan demokratis sesuai dengan jati diri bangsa.

Adapun masalah yang telah teridentifikasi, yaitu: Kurangnya partisipasi siswa dalam proses pembelajaran, Guru kurang inovatif dan kreaktif dalam menggunakan alat peraga, Seringnya guru kurang menguasai materi ajar.

Maka peneliti membatasi masalah yang akan diteliti secara khusus pada peranan model Kooperatif Tipe Snowball Throwing untuk meningkatkan hasil belajar.

Rumusan masalah yang
diajukan oleh PTK, yaitu: Bagaimanakah caranya guru dalam memberikan materi pembelajaran PKn dapat menciptakan suasana yang menyenangkan bagi siswa?. Apakah dengan model Snowball Throwing hasil belajar siswa dapat meningkat?.

Tujuan penelitian dengan model pembelajaran Tipe Snowball Throwing adalah: Meningkatkan hasil belajar siswa pada mata pelajaran PKN dengan menggunakan hasil dari siklus 1 dan siklus 2 . Meningkatkan cara mengajar guru agar terciptanya suasana yang menyenangkan sehingga siswa dapat menerima dan menguasai materi pembelajaran dengan baik.
METODE

PENELITIAN

Penelitian Tindakan kelas ini berlokasi di SD Negeri 163084 yang berada di Jalan Tuanku Imam Bonjol Kelurahan Tebing Tinggi lama Kecamatan TebingTinggi Kota. Subjek dalam penelitian ini adalah siswa kelas IV SD Negeri 163084 KotaTebing Tinggi . Dengan jumlah Siswa 35 orang, terdiri dari 14 siswa laki-laki dan 21 orang perempuan.

Penelitian dilakukan dengan 2 (dua) siklus. Berikut ini adalah rincian waktu/tanggal pelaksanaan penelitian:

a. Persiapan minggu pertamatanggal 01 s/d 06 September 2017.

b. Pelaksanaan siklus I dilaksanakan pada tanggal 08 September s/d 04 Oktober 2017.

c. Pelaksanaan siklus II dilaksanakan 06 Oktober s/d 01 Nopember 2017.

d. Pengumpulan data dan Penyusunan laporan tanggal 10 s/d 26 Nopember 2017.

e. Penyampaian hasil penelitian 03 Desember 2017.

Sebelum masuk pada siklus 1 dilakukan tindakan pendahuluan yang berupa identifikasi permasalahan. 
Siklus spiral dari tahap-tahap penelitian tindakan kelas dapat dilihat pada gambar berikut:



Gambar 1. Siklus Spiral dari Tahap Penelitian

Kegiatan pada setiap tahapan siklus adalah sebagai berikut :

Siklus 1 dilaksanakan pada tanggal 08 Septermber s/d 04 Oktober 2017.

\section{Rencana tindakan}

Pada tahap ini peneliti melakukana beberapa aktivitas yaitu:

a. Menyusun silabus dan RPP tentang materi teks deskriptif yaitu dengan materi "sistem pemerintahan desa dan pemerintah kecamatan". Dalam setiap RPP terdapat kegiatan awal, kegiatan inti, kegiatan akhir dan evaluasi b. Menganalisis materi pelajaran tersebut diatas.

c. Menyiapkan data atau informasi untuk menganalisis materi yang akan dipelajari

d. Menyiapkan siswa membentuk kelompok secara heterogen.

e. Menyiapkan lembar test dan lembar pengamatan (observasi).

f. Menyiapkan alat bantu pembelajaran lainnya.

\section{Tindakan/pelaksanaan (Acting)}

Dalam tahap ini merupakan tahap pelaksanaan apa yang telah tertuang dalam rencana pembelajaran dengan modifikasi pelaksanaan sesuai dengan situasi yang terjadi. 
Langkah-langkah tindakan:

a. Tindakan pertama yang perlu dilakukan adalah mengaktifkan siswa dalam proses pembelajaran dengan memberikan pertanyaanpertanyaan awal untuk membangkitkan motivasi belajar.

b. Guru mengajukan pertanyaan kepada siswa seputar tentang pengetahuan yang berkaitan dengan ssitem pemerintahan yang ada di desa maupun di kecamatan. c.

Guru membagi siswa dalam beberapa kelompok dan disetiap kelompok diberikan tugas simulasi untuk menyebutkan jenis dan sisitem pemerintah desa dan kecamatan

d. Guru dan siswa bersama-sama menyimpulkan hasil pembahasan materi dengan seksama dan tepat.

\section{Observasi (Observing)}

Dalam tahap observasi peneliti melakukan pengamatan selama kegiatan berlangsung, juga teman, guru yang diminta bantuan untuk ikut mengamati selama

kegiatan proses pembelajaran berlangsung dengan menggunakan lembar observasi keaktifan siswa dan lembar observasi aktifitas guru.

\section{b. Refleksi (Reflecting)}

Tahap ini merupakan tahap menganalisa, mensintesa, hasil dari catatan selama kegiatan proses

pembelajaran menggunakan instrumen lembar pengamatan, kuesioner, dan tes. Dalam refleksi melibatkan siswa, teman sejawat yang mengamati dan kepala sekolah.
Siklus ke 2 dilaksanakan pada tamggal 06 Oktober s/d 01 Nopember 2017. Pada siklus kedua ini juga diadakan perencanaan seperti pada siklus satu yaitu tahap perencanaan, tindakan, observasi dan refleksi dalam suatu konsep yang saling terkait.

Instrumen merupakan seperangkat alat untuk memperoleh sejumlah data. Alat pengumpul data dalam penelitian ini adalah tes yang disusun oleh guru.

\section{Jenis Instrumen}

Dalam melaksanakan Penelitian Tindakan Kelas ini, peneliti menggunakan beberapa jenis instrumen, antara lain:

a. Lembar observasi

b. Lembar tes

\section{Analisis Data/Instrumen}

Penelitian ini menggunakan teknik analisis dekriptif kualitatif. Analisis ini dihitung dengan menggunakan statistik sederhana yaitu:

a. Untuk menilai ulangan atau tes formatif

Rata-rata tes formatif dapat dirumuskan :

$$
\overline{\mathrm{X}} 6=\frac{\Sigma x}{\Sigma \mathrm{N}}
$$

$$
\begin{aligned}
& \text { Dengan }: \bar{X} 6=\text { Nilai } \\
& \text { rata-rata } \\
& \sum X 6=\text { Jumlah semua nilai } \\
& \text { siswa } \\
& \sum \mathrm{N}=\text { Jumlah siswa }
\end{aligned}
$$


b. Untuk ketuntasan belajar

Untuk menghitung presentase ketuntasan belajar digunakan rumus sebagai berikut:

$\mathrm{P}=\underline{\Sigma \text { Siswa.yang.tuntas.belajar }} \times 6100 \%$ ¿Siswa

c. Untuk lembar observasi Untuk menghitung lembar observasi pengelolaan model pembelajaranInvestigasi

Kelompok digunakan rumus sebagai berikut :

$\mathrm{X} 6=\frac{P 1+P 2}{2}$

Dimana:

$\mathrm{P} 1$ = Pengamat 1 dan

$\mathrm{P} 2=$ Pengamat 2

Untuk menghitung lembar observasi aktifitas guru dan siswa digunakan rumus sebagai berikut : $x$

$\%=\overline{\sum x} \mathrm{X} 6100 \%$ dengan

$\mathrm{X} 6=\frac{\text { Jumah.hasil. pengamatan }}{\text { Jumlah. pengamatan }}=\frac{P 1+P 2}{2}$

Dimana :

$\%=$ Presentase pengamatan

X 6 = Rata-rata

$\sum X 6=$ Jumlah rata-rata

$\mathrm{P} 1=$ Pengamat 1

$\mathrm{P} 2$ = Pengamat 2

\section{HASIL PENELITIAN DAN PEMBAHASAN}

Nilai KKM untuk PKn adalah70. Sebanyak 22 orang peserta didik $(62,86 \%)$ mendapatkan nilai $<70$ dengan nilai terendah adalah 49 . Sementara itu sebanyak 13 orang peserta didik $(62,86 \%)$ meperolehan nilai $\geq 70$ dengan nilai tertinggi 86 (KKM tuntas).

Hal ini disebabkan karena kurang dipahaminya pelajaran sistem pemerintahan desa dan pemerintah kecamatan yang hanya diberikan guru melalui teori dan penjelasan di papan tulis.

Setelah dilaksankan siklus I dari tanggal 08 September s/d 04 Oktober 2017, maka hasil yang diperoleh antara lainnya:

Pada siklus I, kegiatan belajar mengajar dengan metode pembelajaran yang Snowball throwing telah mengalami peubahan sedikit meningkat dari sebelumnya.

Peran guru masih cukup dominan untuk memberikan penjelasan dan arahan, hal ini disebabkan karena model tersebut masih dirasakan baru oleh siswa. Siswa masih kesulitan dalam kegiatan pembelajaran karena belum terbiasa dengan metode pembelajaran Snowball Throwing.

Hasil siklus I yang didapat pada tabel di atas adalah dari 35 orang peserta didik terdapat 20 orang peserta didik $(57,14 \%)$ mendapatkan nilai $\geq 70$ dengan nilai tertinggi 90 , sedangkan sebanyak 15 orang peserta didik(42,86\%) mendapatkan nilai $\leq 70$ dengan nilai terendah 30 .

Beberapa aspek yang mendapat nilai kurang baik di atas merupakan suatu kelemahan yang terjadi pada siklus I dan akan dijadikan bahan kajian untuk refleksi dan revisi yang akan dilakukan pada siklus II. 
Siklus II yang dilaksanakan pada tanggal 06 Oktober s/d 01 Nopember 2017, telah menggunakan alat peraga berupa gambar-gambar (poster) sebagai pelengkap proses pembelajaran .Hasil berlajar pun telah mengalami peningkatan pada siklu II ini. Berikut ini adalah hasil yang di dapat pada siklus II.

Tercatat dari 35 orang siswa, yang mencapai nilai $\mathrm{KKM} \geq 70$ sebanyak31 orang perserta didik dengan nilai tertinggi 95 dinyatakan tuntas dan yang nilai di bawah KKM dibawah sebanyak 4nilai terrendah 63dan dinyatakan tidak tuntas.

Pada tahap ini, Nilai yang diperoleh anak didik semakin meningkat. Dapat dilihat dari jumlah ketuntasan siswa. Sikap dan perilaku anak dapat dikemukakan sebagai berikut:

a. Siswa senang dengan mata pelajaran yang diajarakan.

b. Siswa tertarik dengan materi pelajaran.

c. Siswa cukup aktif mendengarkan penjelasan guru saat KBM. d. Tertarik dan senang dengan media yang digunakan.

e. Siswa dapat menerima pelajaran dengan baik.

f. Siswa aktif menjawab pertanyaan guru dan mau berebut mengerjakan

g. tugas dan mengerjakan soal latihan dipapan tulis.

h. Semangat siswa dalam mengikuti KBM meningkat.

i. Siswa aktif mengerjakan tugas dari guru.

j. Siswa sudah dapat mengerjakan tugas dari guru dengan baik.

k. Siswa dapat mengerjakan soal test dengan baik.

\section{Pembahasan}

Berdasarkan pemaparan di atas, maka peneliti merangkum ke dalam sebuah tabel agar dapat dengan mudah dipahami dan dilihat dengan cepat bagaimana peningkatan belajar siswa yang dilihat dari observasi dan tes

Tabel 1. Hasil Tes Setiap Siklus

\begin{tabular}{c|c|c|c}
\hline Keterangan & $\begin{array}{c}\text { Sebelum } \\
\text { Tindakan }\end{array}$ & Siklus I & Siklus II \\
\hline Nilai Tertinggi & 86 & 90 & 95 \\
\hline Nilai Terendah & 49 & 30 & 63 \\
\hline Rata-rata Nilai Siswa & 66,54 & 70,06 & 80,00 \\
\hline Ketuntasan Belajar Siswa & 50,00 & 63,33 & 85,71 \\
\hline
\end{tabular}

Uraian pembahasan

didasarkan atas hasil pengamatan yang dilihat dari tes siswa. Dari 35 siswa ternyata banyak siswa yang kurang aktif atau tidak aktif dalam mengikuti proses belajar mengajar pada siklus I tetapi pada siklus II sudah mulai ada peningkatan untuk 
keaktifan dan ketuntasan nilai tes belajar. Terjadinya ketidak aktifan siswa disebabkan karena model pembelajaran yang baru dikenal, juga karena pembagian kelompok yang kurang memperhatikan penyebaran tingkat kecerdasan anak. Tetapi jika siswa sudah memahami dan pembagian kelompok itu adil maka terlihat jelas keaktifan siswa.

Tabel 2. Daftar Perkembangan Nilai Siklus I dan II

\begin{tabular}{l|c|c}
\hline \hline \multicolumn{1}{c|}{ Data } & Siklus I & Siklus II \\
\hline Nilai Terendah & 30 & 63 \\
\hline Nilai Tertinggi & 90 & 95 \\
\hline Rata-rata & 70,06 & 80,00 \\
\hline Nilai $>70$ & $57,14 \%$ & $88,57 \%$ \\
\hline \hline
\end{tabular}

Berdasarkan data tentang hasil belajar selama proses penelitian dari siklus I sampai dengan siklus II, maka dapat dikatakan bahwa proses pembelajaran telah berhasil, karena rata-rata kelas 80, 00 dan secara klasikal siswa yang memperoleh nilai di atas 70 mencapai 88,574\%.

Tabel 3. Perbandingan Siklus I dan Siklus II

\begin{tabular}{l|c|c}
\hline \multicolumn{1}{c|}{ Data } & Siklus I & Siklus II \\
\hline Nilai terendah & 90 & 95 \\
\hline Nilai tertinggi & 30 & 63 \\
\hline Rata-rata nilai & 70,06 & 80,00 \\
\hline Siswa belajar tuntas & 20 & 31 \\
\hline Siswa belajar yang belum tuntas & 15 & 4 \\
\hline
\end{tabular}

\section{SIMPULAN}

Berdasarkan penelitian yang telah dilakukan maka dapat disimpulkan bahwa:

a. Dengan menerapkan model Snawball Throwing dapat meningkatkan hasil belajar siswa.

b. Penggunaan media pembelajaran dengan menerapkan pembelajaran secara kelompok-kelompok dapat meningkatkan hasil belajar siswa dan dapat dilihat dari hasil ulangan siswa persiklus yaitu pada perolehan siklus I adalah 70,06 dan pada siklus II naik menjadi 80,00 .

\section{DAFTAR RUJUKAN}

Abdurrahman, M. 2003. Pendidikan Bagi Anak Berkesulitan Belajar. Jakarta: Rineka Cipta. Amin, Z. I. 2006. Materi Pokok Pendidikan Kewarganegaraan. Jakarta: Universitas Terbuka. 
Baharuddin dan Esa Nur Wahyuni. 2007. Teori Belajar dan

Pembelajaran. Yogyakarta: RUZZ Media.

Depdiknas. 2007. Pedoman Pengembangan Silabus dan Model Pembelajaran. Buku IV. Jakarta: Dikmenum Depdiknas.

Solihatin, Etin dan Raharjo. 2007. Cooperative Learning Analisis Model Pembelajaran PKn. Jakarta: Bumi Aksara.

Habiburrohman, Sadiman dan Samidi. 2012. Peningkatan Hasil Belajar PKn Melalui

Cooperative Learning. Surakarta: Universitas Sebelas Maret.

Isjoni. 2009. Cooperative Learning Mengembangkan Kemampuan Belajar Bekelompok. Bandung: Alfabeta.

Istadi, I. 2005. Agar Anak Asyik

Belajar. Bekasi: Pustaka Inti.

Jamli, Edison, dkk. 2005.

Kewarganegaraan. Jakarta: Bumi Aksara.

Lukum, R. 2013. Peran Ideologi Pancasila Dalam Kebijakan Politik Luar Negeri Indonesia Sebagai Solusi Menghadapi Pengaruh Globalisasi. Gorontalo: Universitas Gorontalo.

Martati, Badruli. 2010. Metodelogi Pembelajaran Pendidikan Kewarganegaraan. Genesindo. Bandung.

Muhibbin Syah. 2005. Psikologi Pembelajaran. Jakarta: Raja Grafindo Persada.
Dimyati dan Mudjiono. 2002. Belajar dan Pembelajaran. Jakarta: Rineka Cipta.

Slavin, Robert E. 2005. Pembelajaran Kooperatif. Alih bahasa: Mohamad Nur,dkk. Surabaya: Pusat Sains dan Matematika sekolah UNESA.

Subhan Sofhian dan Sahid Gatara. 2011. Pendidikan Kewarganegaraan (Civic Education). Bandung: Focusmedia.

Sudjana, Nana. 2010. Dasar-dasar Proses Belajar Mengajar. Bandung: Sinar Baru Algesindo.

Purwanto. 2011. Evaluasi Hasil Belajar. Yogyakarta: Pustaka Pelajar. 